\title{
SH2-PLA: a sensitive in-solution approach for quantification of modular domain binding by proximity ligation and real-time PCR
}

\author{
Christopher M. Thompson, Lee R. Bloom, Mari Ogiue-Ikeda and Kazuya Machida*
}

\begin{abstract}
Background: There is a great interest in studying phosphotyrosine dependent protein-protein interactions in tyrosine kinase pathways that play a critical role in many aspects of cellular function. We previously established $\mathrm{SH} 2$ profiling, a phosphoproteomic approach based on membrane binding assays that utilizes purified Src Homology 2 (SH2) domains as a molecular tool to profile the global tyrosine phosphorylation state of cells. However, in order to use this method to investigate $\mathrm{SH} 2$ binding sites on a specific target in cell lysate, additional procedures such as pull-down or immunoprecipitation which consume large amounts of sample are required.

Results: We have developed PLA-SH2, an alternative in-solution modular domain binding assay that takes advantage of Proximity Ligation Assay and real-time PCR. The SH2-PLA assay utilizes oligonucleotide-conjugated anti-GST and anti-EGFR antibodies recognizing a GST-SH2 probe and cellular EGFR, respectively. If the GST-SH2 and EGFR are in close proximity as a result of SH2-phosphotyrosine interactions, the two oligonucleotides are brought within a suitable distance for ligation to occur, allowing for efficient complex amplification via real-time PCR. The assay detected signal across at least 3 orders of magnitude of lysate input with a linear range spanning 1-2 orders and a low femtomole limit of detection for EGFR phosphotyrosine. SH2 binding kinetics determined by PLA-SH2 showed good agreement with established far-Western analyses for A431 and Cos1 cells stimulated with EGF at various times and doses. Further, we showed that PLA-SH2 can survey lung cancer tissues using $1 \mu$ l lysate without requiring phospho-enrichment.

Conclusions: We showed for the first time that interactions between SH2 domain probes and EGFR in cell lysate can be determined in a microliter-scale assay using SH2-PLA. The obvious benefit of this method is that the low sample requirement allows detection of $\mathrm{SH} 2$ binding in samples which are difficult to analyze using traditional protein interaction assays. This feature along with short assay runtime makes this method a useful platform for the development of high throughput assays to determine modular domain-ligand interactions which could have wide-ranging applications in both basic and translational cancer research.
\end{abstract}

Keywords: SH2, Proximity ligation, SH2-PLA, Modular protein domains, EGFR signaling

\section{Background}

An important consequence of reversible phosphorylation of tyrosine residues on proteins is the creation of binding sites for phosphotyrosine recognizing domains such as Src homology 2 (SH2) and phosphotyrosine binding (PTB) domains $[1,2]$. The human proteome contains

\footnotetext{
* Correspondence: machida@uchc.edu

Raymond and Beverly Sackler Laboratory of Genetics and Molecular Medicine, Genetics and Genome Sciences, University of Connecticut School of Medicine, 400 Farmington Avenue, 06030 Farmington, CT, USA
}

$120 \mathrm{SH} 2$ domains in 110 distinct proteins, and proteinprotein interactions mediated by $\mathrm{SH} 2$ domains play a critical role in essential cellular processes such as cell growth, migration, differentiation, and survival [3, 4]. We and others have utilized $\mathrm{SH} 2$ domains as a tool to profile the global tyrosine phosphorylation state of cells [5-9]. SH2 profiling is a unique proteomic method in which interactions between an array of $\mathrm{SH} 2$ domains and protein samples are quantitatively analyzed, thereby defining the functional output of tyrosine phosphorylation. There are three assay platforms for $\mathrm{SH} 2$ profiling: 
quantitative far-Western, rosette, and oligonucleotidetagged multiplex (OTM) assays [10]. In far-Western, protein samples are separated by electrophoresis and replicate blots are separately probed with labeled $\mathrm{SH} 2$ domains $[6,9]$. In rosette assay, samples are spotted on a membrane, and the binding assay is carried out in a 96-well plate [7]. The labeled $\mathrm{SH} 2$ domain probes are incubated with multiple sample spots in a noncompetitive manner (single $\mathrm{SH} 2$ per well). In an oligonucleotidetagged multiplex (OTM) assay, a mixture of $\mathrm{SH} 2$ domains with domain-specific DNA tags are incubated with a sample spot allowing for competitive binding (single sample per well) [8]. Signal is detected either by chemiluminescence (far-Western and rosette) or by PCR (OTM). Quantified values are used to classify samples, such as different cancer tissues, based on $\mathrm{SH} 2$ binding preferences $(\mathrm{SH} 2$ profiles) $[5,6,9,10]$.

One limitation of current $\mathrm{SH} 2$ profiling methods is that these assays themselves do not provide the identity of the binding proteins. When the sample identity is known, such as synthesized peptides or purified proteins, this is not a problem. However, for samples with more complexity such as cell lysate and tissue, it is often difficult to infer the identity of detected SH2 binding proteins unless a literature/database search can provide a helpful clue. In this case, additional experimental methods such as antibody-based or mass spectrometry-based protein identification must be combined with $\mathrm{SH} 2$ profiling. For example, in order to identify a band detected by SH2-farWestern, a pull down assay combined with Western blotting with specific antibodies (for few candidate proteins) or MS identification (for an unknown set of proteins) is needed $[5,7]$. Further, those additional assays often require a large amount of sample, are labor intensive and not always successful [11]. These laborious, costly procedures are required for even a simple task such as validating the binding of $\mathrm{SH} 2$ domains to a few candidate proteins (e.g., EGFR, ErbB2, etc.) which have been inferred from $\mathrm{SH} 2$ profiling.

Proximity ligation assay (PLA) is a molecular recognition assay that depends on the ligation of two oligonucleotidetagged probes that are capable of forming a complex, when binding to a target (or targets) that are in close proximity to each other $[12,13]$. The method was originally described using aptamers as affinity reagents [14], and in its current version is performed using antibodies to determine protein expression and interactions in situ or in solution [15-18]. Various commercial PLA kits are available mainly from Olink Bioscience and Applied Biosystems. Of these, Applied Biosystems TaqMan Protein Assays are designed to quantify target protein expression levels using a small amount of cell lysate $(2-3 \mu \mathrm{l})[19,20]$. The system uses TaqMan technology, an established platform for quantification of gene expression based on quantitative real-time
PCR. The standard TaqMan Protein Assay kit was originally designed to detect stem cell markers, while an open kit is available for use with custom antibodies [20]. Although homogenous PLA has been used to determine protein expression in lysate [21,22], we hypothesized that the system could be customized for detection of $\mathrm{SH} 2$ domain-based protein-protein interactions in solution. A PLA-based SH2 profiling method would have multiple advantages such as low sample requirement, higher sensitivity, and rapid validation of $\mathrm{SH} 2$ binding protein identity. Here, using activated epidermal growth factor receptor (EGFR) as the SH2 binding target, we have developed and validated such an assay, termed SH2-PLA, which has a broad range of detection, performance equivalent to far-Western, and potential application in translational research [23-25].

\section{Results}

\section{SH2-PLA assay scheme}

We chose the epidermoid carcinoma cell line A431, which overexpresses wild type epidermal growth factor receptor (EGFR), as a developmental platform. The premise of the SH2-PLA assay is that 1) EGF stimulation induces tyrosine phosphorylation of the intracellular domain of EGFR, which creates specific binding sites for SH2 domains such as Grb2, Src, PLCy1, Vav2, etc.; 2) GST-SH2 domain coupled to anti-GST 5' Prox-Oligo binds to these phosphotyrosines in cell lysate; 3) This interaction brings the anti-GST 5 ' Prox-Oligo and antiEGFR 3' Prox-Oligo probes together in close proximity, thus allowing for the proximity ligation reaction to be subsequently quantified by real-time PCR (Fig. 1). In other words, detection of a specific assay signal requires the creation of the quaternary complex: anti-EGFR 3' Prox-Oligo probe:phosphorylated EGFR:GST-SH2 protein:anti-GST 5' Prox-Oligo probe.

\section{Performance of TaqMan protein expression assay}

Prior to customizing the TaqMan Protein Expression Assay for SH2-PLA (i.e., modular domain binding assay), we tested the performance of the original proximity ligation assay using the kit-supplied anti-ICAM1 assay probes and Raji B-cell lymphoma lysate. The 3' and 5' oligonucleotide-conjugated anti-ICAM1 assay probes were incubated with the Raji lysate for $60 \mathrm{~min}$ followed by the ligation reaction. After heat inactivation, the ligation product was quantified using the TaqMan real-time PCR system. The experiment was performed in a 96 well plate with approximately three hours of assay time. We observed, with high-precision, approximately three orders of magnitude of linear dynamic range for a cell input of $0.24-250$ cells per $\mu \mathrm{l}$ (intra-assay $\% \mathrm{CV}<1.1 \%$ ) (Additional file 1: Figure S1A). When two independent experiments were compared, they showed very strong correlation 

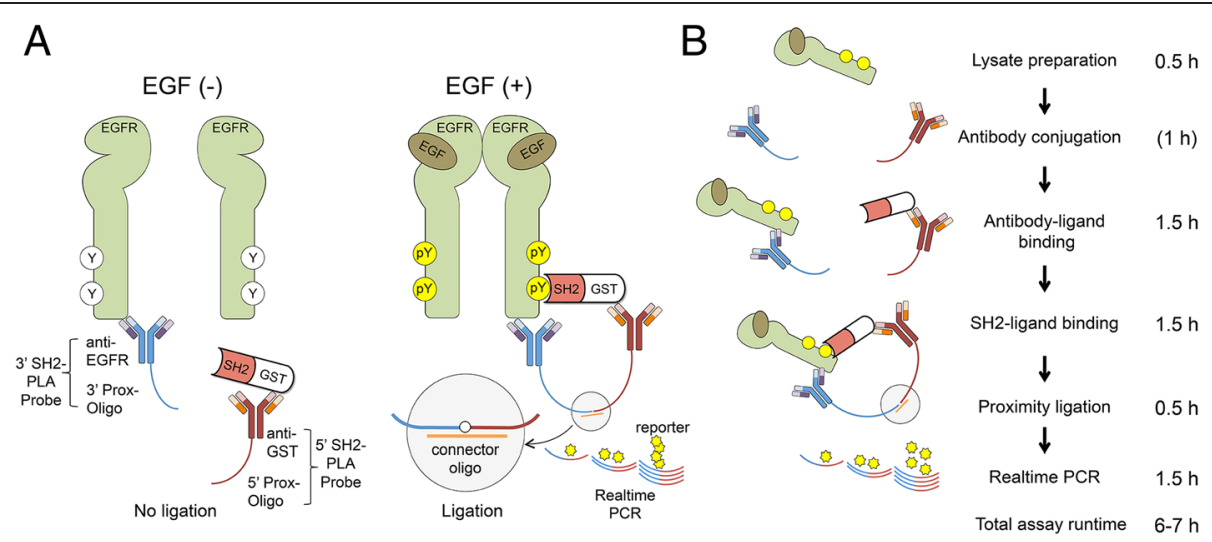

Fig. 1 In-solution SH2 domain binding assay using proximity ligation and real-time PCR. a, Schematic Illustration of SH2-PLA. A pair of PLA probes is used to detect the interaction of tyrosine phosphorylated EGFR and a GST-SH2 domain. The 3' SH2-PLA probe consists of an anti-EGFR antibody conjugated with the 3' proximity oligonucleotide (3' Prox-Oligo). The 5' SH2-PLA probes consists of an anti-GST antibody conjugated with the 5' Prox-Oligo and a GST-SH2 domain. When the GST-SH2 domain binds to tyrosine phosphorylation sites of EGFR, the 5' and 3' PLA probes are brought in close proximity, allowing ligation of the two Prox-Oligos which is detectable by real-time PCR. $\mathbf{b}$, Experimental workflow of SH2-PLA Method 1. Lysates are prepared with or without EGF stimulation. Biotinylated anti-GST and anti-EGFR antibodies are conjugated with the $5^{\prime}$ and $3^{\prime}$ Prox-Oligos, respectively, and stored at $-20^{\circ} \mathrm{C}$. The $5^{\prime} \mathrm{SH}$-PLA probe is mixed with purified GST-SH2, and the $3^{\prime} \mathrm{SH} 2-\mathrm{PLA}$ probe is mixed with cell lysates allowing the antibodies to bind their respective epitopes. Subsequently, the $5^{\prime}$ and $3^{\prime}$ PLA probe solutions are combined to induce interaction between the SH2 and pEGFR. Then, the amount of the complex is quantified by proximity ligation and real-time PCR. An alternative method is also possible (Additional file 1: Figure S2). Estimated assay runtime including sample-handling steps for each procedure is noted on the right

(Pearson correlation $r=0.99$ ) (Additional file 1: Figure S1B). We concluded that the performance of the TaqMan Protein Expression Assay was sufficient for development of an $\mathrm{SH} 2$ domain binding assay.

\section{Development of the SH2-PLA assay}

Biotinylated anti-GST and anti-EGFR polyclonal antibodies were conjugated with $5^{\prime}$ and $3^{\prime}$ oligonucleotides following the probe development protocol (see Methods). To evaluate the anti-GST probes (5' Prox-Oligo- and 3' Prox-Oligo-conjugated anti-GST antibodies) and anti-EGFR probes (5' Prox-Oligo- and 3' Prox-Oligoconjugated anti-EGFR antibodies), purified GST protein and A431 cell lysate were serially diluted and respective TaqMan protein expression assays were performed as in the ICAM1 expression assay. In these separate detection experiments for GST and EGFR, we observed that the GST probe had a linear increase in Ct values between 0.13 and $4.17 \mathrm{nM}$ of GST input, while the EGFR probe for A431 lysate was linear from 1.9 to $30 \mu \mathrm{g} / \mathrm{ml}$ (Additional file 1: Figure S1C and D).

Next we tested the ability of the $5^{\prime}$ Prox-Oligoconjugated anti-GST antibody and 3' Prox-Oligoconjugated anti-EGFR antibody pair to detect an interaction between the GST-SH2 and EGFR in A431 lysate. Among multiple attempts performed to optimize the binding conditions, we found two distinct methods that provided a favorable signal-to-noise profile (Fig. 1b \& Additional file 1: Figure S2). In Method 1, antibodies are premixed with target proteins prior to $\mathrm{SH} 2$ binding, while in Method 2, GST-SH2 domains and EGFR (lysate) are incubated prior to antibody binding (See Methods for more details). As the results from both methods were nearly equivalent, Method 1 (Fig. 1b) was used for all experiments described in this report.

\section{Specificity of the SH2-PLA}

A431 cell lysates were prepared in the presence or absence of EGF stimulation and the SH2-PLA assay was performed as outlined in Fig. 1b. We employed several $\mathrm{SH} 2$ domain containing proteins for validation that are known to be physiological ligands of EGFR such as Grb2, Vav2, and PLCY1 [26-28]. Figure 2a shows a representative real-time $\mathrm{PCR}$ amplification plot of the SH2-PLA assay using the Grb2 $\mathrm{SH} 2$ domain probe and A431 cell samples. PCR product in the EGF-stimulated A431 sample was amplified more rapidly than in the unstimulated sample resulting in a lower threshold cycle $(\mathrm{Ct})$ value. The difference in $\mathrm{Ct}$ values between the two samples $(\Delta \mathrm{Ct})$ is an indicator of enhanced binding by the Grb2 SH2 domain probe to tyrosine phosphorylated EGFR (pEGFR). To validate the specificity of the assay, we compared signal from a GST-SH2 domain probe and GST control. The Ct value for the GST control was unchanged with EGF stimulation (lanes 1 vs. 2, Fig. 2b upper panel). On the other hand, the $\mathrm{SH} 2$ domains of Grb2 and PLC $\gamma 1$ showed a marked reduction in their $\mathrm{Ct}$ values upon stimulation (lanes 5 vs. 6 and 9 vs. 10). Using the same set of samples and $\mathrm{SH} 2$ domains, farWestern blotting was performed as a reference (Fig. $2 \mathrm{~b}$ middle panel). In far-Western, proteins were separated on polyacrylamide and transferred to a nitrocellulose 

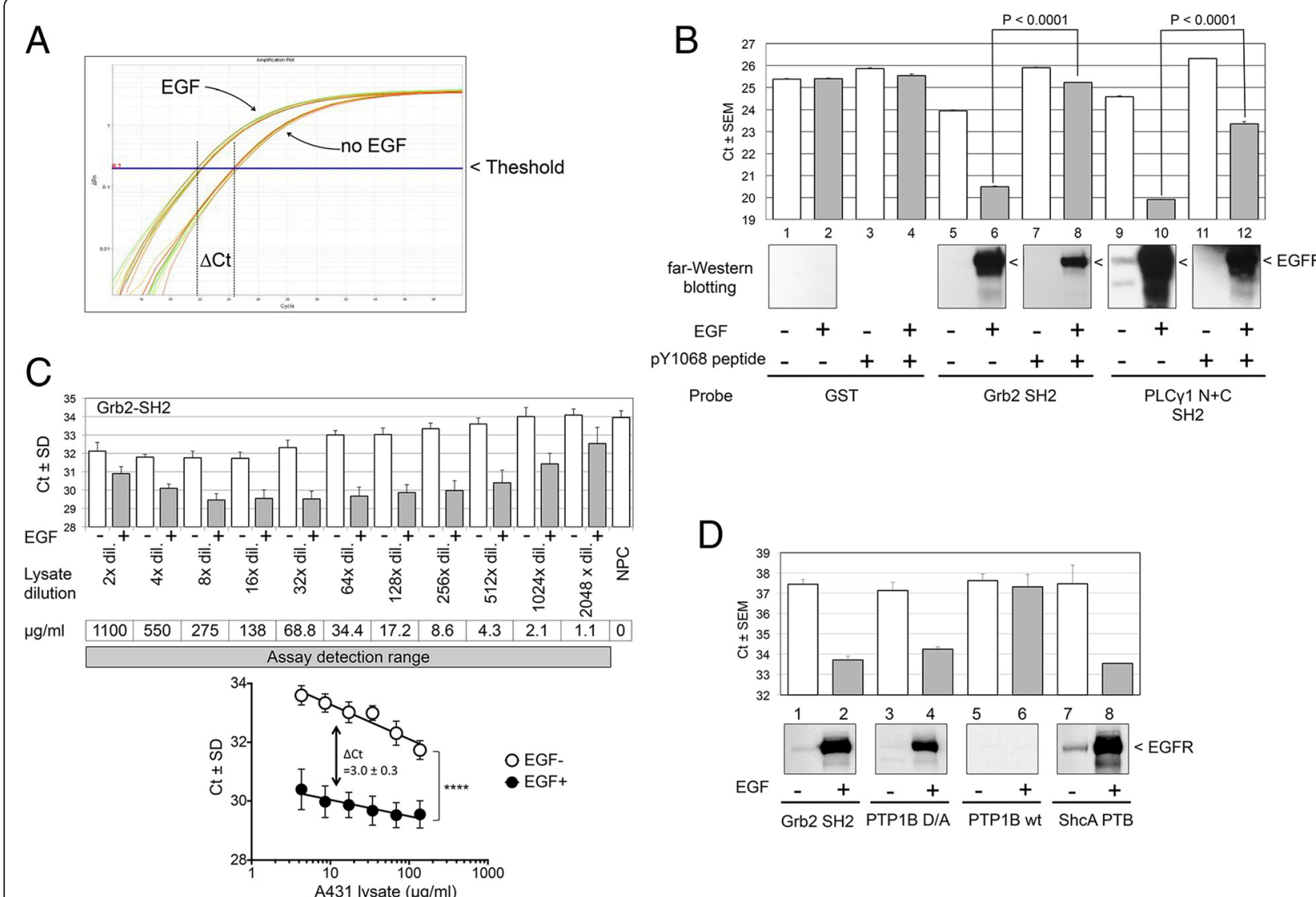

Fig. 2 Validation of the SH2-PLA assay. a, Representative PCR amplification plot for SH2-PLA experiments. Increased binding between SH2 and pEGFR upon EGF stimulation is expressed as a reduced threshold cycle value $(\mathrm{Ct})$. Here, $\Delta \mathrm{Ct}$ is defined as [Ct $\mathrm{Ct}_{\text {control }}-\mathrm{Ct}_{\mathrm{EGF}}$ stimulated]. b, Specificity of SH2-PLA. SH2-PLA (top panel) and far-Western (middle panel) results for EGF-stimulated and control A431 cell samples are shown. Results for GST control probe are shown in lanes 1-4; Grb2 SH2 probe in lanes 5-8; and PLCY1 tandem SH2 probe in lanes 9-12. Lanes 3, 4, 7, 8, 11, and 12 show the assay result in the presence of pY1068 blocking peptide, which contains the Grb2 SH2 consensus binding site of EGFR. c, SH2-PLA assay performance. The SH2-PLA assay was performed three times using a two fold dilution series of EGF-stimulated and control A431 cell lysates. Average Ct values, normalized to non protein control (NPC), are shown in the upper panel. The intra-assay variation for Ct values was $0.07-2.36$ (mean 0.60) and the inter-assay \%CV was 0.32-3.08 (mean 1.28). Since EGF-stimulated samples always showed a greater signal (lower Ct) than the unstimulated control throughout the dilution series, the range of assay detection is estimated to be at least $1.1-1100 \mu \mathrm{g} / \mathrm{ml}$ of lysate concentration, and the lower limit of detection is approximately $2 \mathrm{ng}$ of protein per assay. The lower panel shows the approximately linear region of the mean $\mathrm{Ct}$ plot against log input lysate concentrations, and the $\Delta C t$ (unstimulated - stimulated) of about three cycles. The $\log _{2}$ fold change between EGF-stimulated and control samples was estimated to be 6.0 - 6.4 using the ProteinAssist software tool (Additional file 1: Figure S3). d, Adoption of other phosphotyrosine recognizing domains. The SH2-PLA methodology was applied to protein tyrosine phosphatase (PTP) and phosphotyrosine binding (PTB) domains. ShcA PTB domain and the substrate-trapping mutant of PTP1B PTP domain displayed activity comparable to Grb2 SH2 (lanes 1-4 and 7-8). Signal was undetectable for the wild type (wt) PTP1B PTP domain, likely due to the intrinsic phosphatase activity (lanes 5-6)

membrane which was then probed with HRP-labeled GST-SH2 domains [23]. The identity of a major band at approximately $180 \mathrm{KDa}$ in the SH2-far-Western blotting has previously been confirmed to be EGFR by antiEGFR immunodepletion (data not shown). As shown in the middle panel of Fig. $2 \mathrm{~b}$, the signal profiles of the SH2-PLA and far-Western are similar despite their use of distinctive assay readouts (Ct values vs. bands). $\mathrm{SH} 2$ domains are known to have both unique and overlapping ligand binding characteristics [7, 29-32]. To determine if the $\mathrm{SH} 2$ binding is tyrosine site dependent, a synthesized phosphopeptide corresponding to EGFR tyrosine 1068, containing the Grb2 SH2 consensus binding site, was added as a blocker. In both assays, Grb2 SH2 binding was significantly reduced in the presence of the blocker, while the blocking effect on PLCY SH2 domain binding was relatively modest (lanes 6 vs. 8 and 10 vs. 12). Taken together, these results indicate that, like farWestern, the SH2-PLA assay performed with the anti-GST 5' Prox-Oligo antibody and anti-EGFR 3' Prox-Oligo antibody probe pair is specific enough to distinguish between EGF-stimulated and control cell samples. 


\section{Performance of the SH2-PLA assay}

To evaluate assay performance, including the limit of detection, linearity, and precision, we performed the SH2-PLA assay using a serial dilution of lysate. In a 96 well plate, EGF-stimulated and control A431 cell lysates at concentrations between 1.1 and $1100 \mu \mathrm{g} / \mathrm{ml}$ were incubated with the Grb2 $\mathrm{SH} 2$ probe. Surprisingly, at all 11 lysate concentrations tested, EGF-stimulated samples showed a greater signal (lower Ct value) than unstimulated samples, demonstrating the high sensitivity of the system (limit of detection: $\sim 1 \mu \mathrm{g} / \mathrm{ml}$ or $2 \mathrm{ng}$ protein per assay). However, at higher lysate concentrations (>300 $\mu \mathrm{g} / \mathrm{ml}$ ), suppressed signal was observed (Fig. 2c upper panel), consistent with other reports using homogeneous proximity ligation assays [12, 19, 22]. This is often referred to as the "high-dose hook effect" and has been observed in other antibody based assays [33-35]. As a result, the assay had a linear signal response range of a 1-2 order of magnitude (Fig. 2c lower panel). In addition, the slopes of stimulated and unstimulated samples, an indicator of PCR amplification efficiency, were slightly different suggesting that conventional $\Delta \Delta \mathrm{Ct}$ or standard curve methods are not suitable for relative quantification of $\mathrm{SH} 2$ binding. Therefore, we utilized ProteinAssist, a software tool designed for fold change estimation in TaqMan Protein Expression Assays based the $\Delta \mathrm{Ct}$ squared method [12]. With this method, the $\log _{2}$ fold change between EGF-stimulated and control samples was estimated to be 6.0 - 6.4 (Additional file 1: Figure S3). Based on three independent assays, the intraassay variation of $\Delta \mathrm{Ct}$ values was $0.07-2.36$ (mean 0.60 ) and the inter-assay \%CV was 0.32-3.08\% (mean $1.28 \%$ ). Taken together, these results suggest that the limit of detection and precision are favorable, but the linear signal response range is modest, likely due to the binding characteristics of antibodies and probes.

\section{Application to other $\mathrm{pTyr}$ recognition domains}

In addition to $\mathrm{SH} 2$ domains, members of the phosphotyrosine binding (PTB) and tyrosine phosphatase (PTP) domain families are also known to recognize phosphotyrosine residues and play regulatory roles in tyrosine kinase pathways [1, 36, 37]. Considering their potential applications in phosphoproteomics research, we tested if the same SH2-PLA methodology is applicable to these domains. GST-fusion proteins of the ShcA PTB domain, wild type PTP1B PTP domain, and catalytically inactive (substrate-trapping) mutant PTP1B PTP domain were purified and subjected to the assay using the same protocol as for SH2 domains. As shown in Fig. 2d, ShcA PTB and the catalytically inactive PTP domain of PTP1B showed binding activity to pEGFR comparable to the Grb2 SH2 domain, while the wild type PTP domain, having intrinsic PTP activity, showed no binding.

\section{Estimation of EGFR phosphotyrosines at the limit of detection}

The serial dilution experiment indicated that the limit of detection is about $2 \mathrm{ng}$ protein per assay in the case of A431 cells, although this threshold could change for other cell lines with different EGFR expression levels. A titration experiment using a "spike-in" pEGFR protein control would address the ambiguity, but preparation of such a reagent is challenging. Therefore, we took a retrospective approach in which a series of quantification methods were combined to measure the absolute amount of EGFR phosphotyrosine in the minimum amount of cell lysate necessary for SH2-PLA.

First, using a baculovirus expression system, we generated recombinant GST fused c-Abl protein to serve as the standard for phosphotyrosine. Then we treated the Abl protein with the tyrosine specific phosphatases PTP1B and TC-PTP. Anti-phosphotyrosine blots of treated and untreated $\mathrm{Abl}$ proteins indicated that phosphorylated $\mathrm{Abl}$ protein was mostly dephosphorylated by phosphatase treatment. Following the treatment, we quantified the amount of free phosphate, which is the hydrolyzed product of phosphotyrosine, using a phosphate standard curve generated with a malachite green phosphatase assay $(\triangle \mathrm{Abl}$ $\mathrm{PO}_{4}^{3-}=5.7 \mathrm{pmol} / \mu \mathrm{g}$, Fig. 3a).

Next, anti-phosphotyrosine dot blotting was performed and the amount of total phosphotyrosine in EGF-stimulated Cos 1 lysate was estimated using the Abl standard (Fig. 3b). Finally, the tyrosine phosphorylation of EGFR was estimated by comparing the EGFR band intensity with the whole band intensity on an antiphosphotyrosine Western blot (Additional file 1: Figure S4). According to these analyses, we estimated that 0.122 pmol phosphotyrosine is present on EGFR in $1 \mu \mathrm{g}$ of EGF-stimulated A431 cell lysate. Thus in 2 ng lysate, which is the quantification limit of SH2-PLA (Fig. 2b), there is $0.243 \mathrm{fmol}$ of phosphotyrosine on EGFR (Fig. 3b). In addition, assuming that A431 has 2.5 million EGFR per cell [38-40] and $150 \mathrm{pg}$ of total protein per cell [41], we estimated that on average 4-5 tyrosines out of 22 putative tyrosine phosphorylated sites [42] per EGFR molecule are phosphorylated in EGF-stimulated A431 cells (Additional file 1: Figure S4).

\section{Practical limit of detection from cell culture}

Since the lysate dilution experiment indicated that the lysate requirement for SH2-PLA is very low, we next determined the lower limit of the assay by cell numbers. Serially diluted A431 cells were seeded in a 96-well plate, starved $16 \mathrm{~h}$, and stimulated with EGF. Cells were lysed in the same volume of buffer and interaction between EGFR and Vav2 SH2 was analyzed by SH2-PLA. As shown in Fig. 4a, the assay detected EGF dependent SH2 interaction in the lysate equivalent of 16 cells (780 cells 

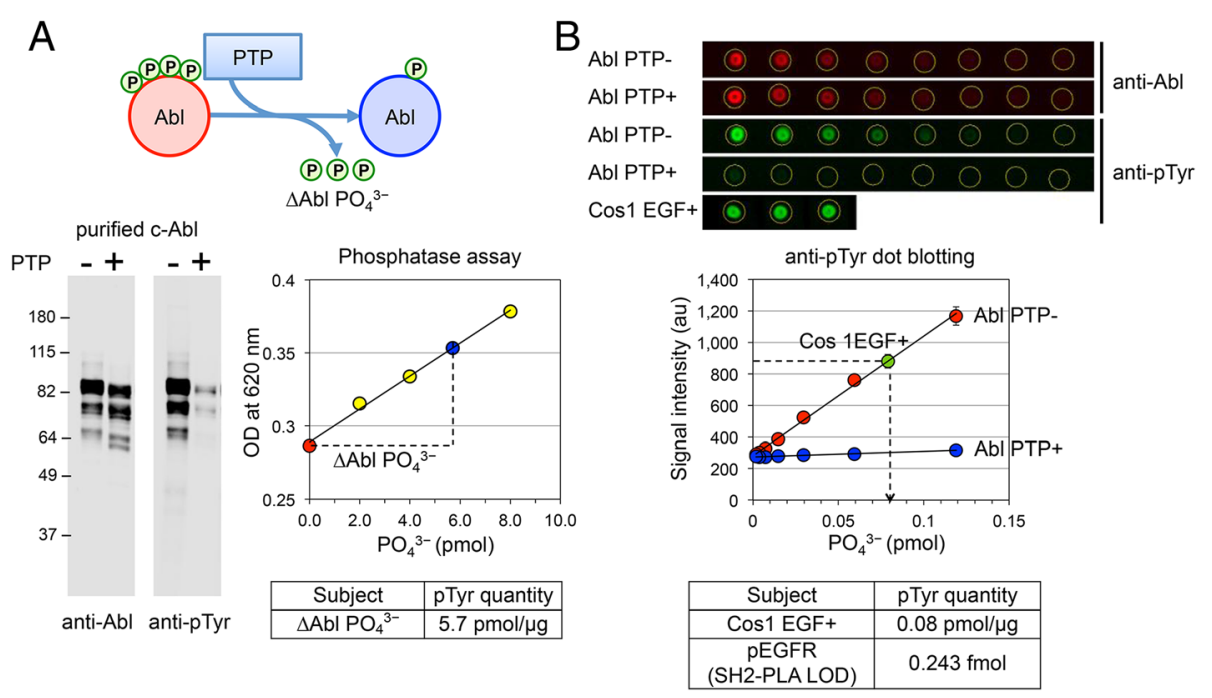

Fig. 3 Estimation of EGFR phosphotyrosines at the limit of detection. To define an absolute lower limit of detection (LOD) for SH2-PLA, the total amount of EGFR phosphotyrosines in sample cell lysate was estimated using a phosphotyrosine standard sample and quantitative dot blotting analyses. $\mathbf{a}$, Recombinant c-Abl protein, the pTyr-standard sample, was treated with tyrosine specific phosphatases PTP1B and TC-PTP. The amount of hydrolyzed phosphotyrosine was quantified by malachite green phosphatase assay ( $\triangle \mathrm{Abl} \mathrm{PO}_{4}^{3-}$ ). Left panel shows anti-Abl and anti-phosphotyrosine blots for phosphatase-treated (Abl PTP+) and -untreated (Abl PTP-) samples. After the PTP treatment, the level of c-Abl tyrosine phosphorylation was greatly reduced but weak phosphorylation was still detectable with longer exposure time. The right panel shows a plot of the phosphate standard used for the quantification. Red circle, untreated c-Abl; blue circle, PTP-treated c-Abl; yellow circles, the kit supplied phosphate standard. From this analysis, $\triangle \mathrm{Abl} \mathrm{PO} 3$ was estimated to be $5.7 \mathrm{pmol}$ per $\mu \mathrm{g}$ of the $\mathrm{c}$-Abl protein. $\mathbf{b}$, Quantitative dot blotting. The total pTyr in the EGF-stimulated Cos 1 cell lysate was estimated from a pTyr standard curve generated from anti-phosphotyrosine dot blotting. Upper panel shows raw anti-Abl and anti-pTyr blots. Serially diluted c-Abl pTyr standard (left to right 3.1-0.02 ng per spot) and $0.01 \mu \mathrm{g}$ EGF-stimulated Cos1 samples were spotted on nitrocellulose membrane (performed in triplicate). The middle panel shows the resulting pTyr standard plot with the quantified signal intensities. The pTyr amount in the EGF-stimulated Cos1 lysate was estimated to be 0.08 pmol per $\mu \mathrm{g}$ lysate. Subsequently, an anti-pTyr Western analysis for A431 and Cos1 samples was performed, relative intensities of the EGFR bands were calculated, and the amount of EGFR pTyr in the EGF-stimulated A431 sample was estimated to be $0.122 \mathrm{pmol} / \mathrm{\mu g}$. Thus $2 \mathrm{ng}$ of EGF-stimulated A431 sample, which is the lower limit for SH2-PLA detection, would contain 0.243 femtomole EGFR pTyr. See Methods and Additional file 1: Figure S4 for more information

per well lysed in $50 \mu \mathrm{l}$ ) or approximately $2.5 \mathrm{ng}$ which is close to the detection limit calculated above (Fig. 2c). In addition to EGFR-overexpressing A431 cells, we performed a similar lysate dilution experiment using EGF stimulated Cos1 cells and found that a lysate concentration approximately four times higher is required for detection, consistent with modest EGFR phosphorylation in Cos1 cells (Additional file 1: Figure S4 and data not shown). These results demonstrate that SH2-PLA is capable of detecting interaction between $\mathrm{SH} 2$ domains and pEGFR using a very small number of cultured cells.

\section{Correlation between SH2-PLA and far-Western in kinetic analyses}

Defining phosphorylation kinetics in growth factor stimulated cells is important in cell signaling studies. We applied the SH2-PLA approach to determine timedependent and dose-dependent changes in SH2 binding to pEGFR using A431 and Cos1 cells (Fig. 4b). For cross-validation, we performed far-Western analysis and compared the results side by side. As shown in Fig. 4b, the dose- and time-dependent increases in Grb2 SH2 binding to EGFR were obvious both by far-Western
( 180 KDa band on upper panel) and SH2-PLA (Ct value in lower panel). When corresponding signal values (band intensity and Ct values) of both assays were compared, there was a high correlation (Pearson coefficient $r=0.97$ ) (Fig. 4c). These results suggest that SH2-PLA is capable of analyzing cells with various levels of EGFR expression and is able to produce quantitative results similar to those obtained from established protein-protein interaction assays (e.g., pull-down and immunoprecipitation) in a significantly shorter assay time while using 10-100 times less sample.

\section{Application of SH2-PLA for cancer tissue analysis}

To explore the translational application of SH2-PLA, we analyzed binding of Grb2 SH2 to EGFR in lung cancer patient tissues. Empirically, the tyrosine phosphorylation analysis of patient-derived solid tumors is challenging due to intrinsically high protease and phosphatase activities requiring phospho-enrichment and larger starting material [43]. We asked if SH2-PLA is capable of detecting a specific signal within human lung cancer tissues without pTyr enrichment. In collaboration with the Haura group at the Moffit Cancer Center, we obtained 


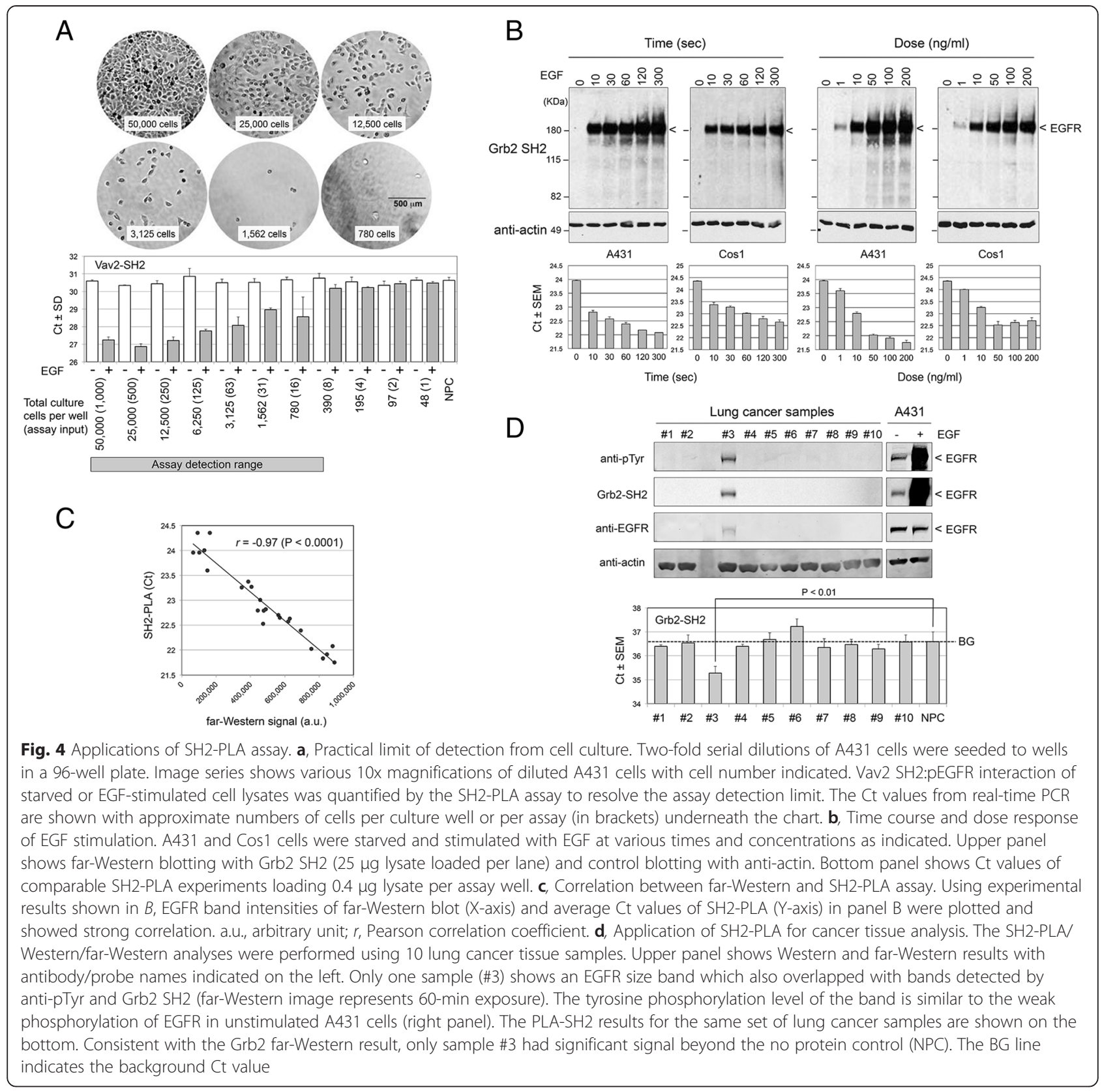

10 non-small cell lung cancer samples in a single-blind manner (neither molecular nor pathological characteristics were provided). We lysed the frozen tissues and performed the SH2-PLA assay (with the Grb2 SH2anti EGFR probe pair), Western blotting (with antiphosphotyrosine antibody), and far-Western blotting (with Grb2 SH2 probe) for comparison (Fig. 4d). In Western and far-Western, only one sample showed tyrosine phosphorylation at a band corresponding to EGFR size (\#3, upper and middle panels). In the SH2-PLA assay using $0.5 \mu \mathrm{g}$ of lysate per assay (equivalent to $\sim 3,000$ cells), we also observed a modest but significant signal (lower $\mathrm{Ct}$ value) in the same sample confirming the presence of tyrosine phosphorylated EGFR (lower panel), even though its level of phosphorylation was significantly lower than that of A431 cell samples (upper right panel). This result indicates that SH2-PLA is capable of detecting tyrosine phosphorylated SH2 domain recognition sites in weakly phosphorylated tumor tissues without requiring phosphopeptide enrichment.

\section{Discussion}

In this study we developed SH2-PLA, a novel insolution $\mathrm{SH} 2$ domain binding assay, to analyze tyrosine phosphorylated EGFR in EGF-stimulated cells. The key feature of this assay is that binding of the $\mathrm{SH} 2$ domain 
probe to its cognate phosphorylated binding sites is monitored in solution using a combination of proximity ligation and quantitative PCR technologies. A positive signal requires the formation of a quaternary protein complex, namely a $5^{\prime}$ oligonucleotide-tagged antiGST antibody (anti-GST 5' Prox-Oligo probe), a GSTSH2 protein, tyrosine phosphorylated EGFR, and a 3' oligonucleotide-tagged anti-EGFR antibody (anti-EGFR 3' Prox-Oligo probe). We identified two stepwise protocols which yielded a suitable signal-to-noise profile: Method 1, pre-incubation of antibody probes to their respective targets (EGFR and GST) followed by SH2 binding; and Method 2, pre-incubation of the $\mathrm{SH} 2$ probe with EGFR followed by antibody binding. For EGF-stimulated A431 cells, we showed that a signal is detectable with as little as 2 ng lysate input per reaction and that the assay is able to detect specific interactions across three orders of magnitude of lysate input. To test the practical application, we conducted phosphorylation kinetics experiments of EGFstimulated cells and observed good agreement between SH2-PLA and the established far-Western assay. Further we showed that SH2-PLA unambiguously detected a relatively low level of EGFR phosphorylation in lung cancer tissues using far less cell lysates than typically available from a core needle biopsy $\left(\sim 10^{5}\right.$ cells or $\left.100 \mu \mathrm{g}\right)$ [44]. These data suggest that SH2-PLA is a promising platform to rapidly determine $\mathrm{SH} 2$ domain binding sites in EGFstimulated cells or cancer tissues using a small amount of sample.

As with other immunoassays such as ELISA and bead arrays, various types of $\mathrm{SH} 2$ and other modular domain binding assays in both solid- and solution-phase platforms have been described [2, 45]. Among those, pull down, far-Western and their derivatives represent the most popular methods to assess $\mathrm{SH} 2$ domain binding sites on target proteins (e.g., pEGFR). In pull down assays, lysate is incubated with bead-bound $\mathrm{SH} 2$ domains for several hours, followed by Western blotting with specific antibodies to the target protein. This assay requires a rigorous washing step and a negative control to minimize signal from non-specific binding and can be confounded by indirect binding via multi-protein complexes. In farWestern blotting, only direct binding between the labeled $\mathrm{SH} 2$ domain and membrane-bound proteins is detected, though the identity of the band may need to be confirmed by immunoprecipitation or other methods. As a result of these multiple procedures, these assays are usually low throughput, requiring $100-1000 \mu \mathrm{g}$ of protein and multiple days of assay runtime. In contrast, SH2-PLA requires only a few microliters of lysate and 6-7 hours of assay time, making this assay highly flexible. Although other high throughput systems, based on microarray or fluorescence polarization, are suitable for global mapping of $\mathrm{SH} 2$ domain binding sites using synthesized peptide libraries
$[29,32,46,47]$, SH2-PLA excels in the detection of SH2 binding to a specific target protein in whole cell lysate without requiring pre-purification or enrichment.

Although the assay sensitivity is high, we observed a relatively modest linear range (1-2 orders of magnitude). It is currently unknown that whether this can be attributed to biochemical characteristics of assay components including buffer solutions, oligonucleotides, antibodies, GST-SH2 domains, and the stoichiometry of tyrosine phosphorylation sites on EGFR. Consistent with our observation (Additional file 1: Figure S1A), the linear range for the TaqMan Protein assay system is reported to be 2-3 orders of magnitude when used to quantify protein expression [12, 20]. The anti-EGFR and GST antibodies used in this study when tested individually showed a lower linear range (Additional file 1: Figure S1C and D). In addition, the SH2-PLA, designed to detect the formation of the quaternary protein complex, may also be affected by the transient nature of $\mathrm{SH} 2$ domain-ligand binding [48-50]. Thorsen et al. have reported a feasibility study correlating the MMP9:TIMP1 protein complex with breast cancer prognosis in which they validated the use of ELISA and PLA-based methods [51]. In this report, they obtained a linear signal range across approximately one order of magnitude in human plasma dilutions (10X to $100 \mathrm{X}$ dilution). Taken together, multiple factors might result in the relatively narrow linear range seen in these protein-protein interaction assays employing in-solution proximity ligation assay. Nevertheless, this issue can be partly addressed by calibration using software tools such as ProteinAssist [12] (Additional file 1: Figure S3). Moreover, in many cases protein interaction assays are qualitative rather than quantitative in which the identification of positive interactions is the priority and high sensitivity and wide detection range, such as that observed in SH2-PLA, is essential.

Performance of SH2-PLA could be improved by modifying the methodology. Firstly, direct labeling of SH2 domains or the GST tag with oligonucleotides would reduce the assay complexity and could prevent issues stemming from insufficient GST:anti-GST antibody binding. Further, if different $\mathrm{SH} 2$ domains are tagged with different oligonucleotides, it would allow for a multiplex PLA reaction analogous to the previously described competitive reverse-phase $\mathrm{SH} 2$ profiling assay [8]. A potential problem with direct tagging is $\mathrm{SH} 2$ domain activity loss due to amino acid modification that would need to be assessed on a domain-by-domain basis. Secondly, solid-phase PLA could be considered. Solidphase PLA uses an additional antibody which captures the target prior to dual recognition with $3^{\prime}$ and $5^{\prime}$ PLA antibody probes [14]. Solid-phase PLA was reported to have a broader dynamic range compared to solution-phase PLA $[52$, 53]. Owing to its additional washing steps, solid- 
phase PLA is likely less affected by the presence of excess unbound PLA probes and interfering substances in the buffer. 4-PLA, a more elaborate variation of solid-phase PLA, is another choice [54]. In 4-PLA, a set of five antibodies consisting of one capture antibody and four oligonucleotide-bound antibodies are employed to attain simultaneous recognition of five epitopes on one or more target molecules. Tavoosidana et al. applied 4-PLA to quantification of prostasome microvesicles, a potential marker of prostate malignancies, in blood samples and showed superior performance over a conventional PLA. A tempting application of this method would be a multiplex modular domain assay targeting multiple PTMs on receptor tyrosine kinases such as EGFR or PDGFR. Receptor PTMs could be monitored by a set of PTM-recognizing domains, e.g., SH2, 14-3-3, etc., allowing for identification of exclusive or simultaneous modifications. The lower background of these solid phase platforms could benefit SH2-PLA with improved overall sensitivity. However additional binding and washing steps will compromise the simplicity of the current SH2-PLA method. More importantly, it remains to be determined if weak SH2-pTyr interactions would be detectable after a stringent wash.

In addition to the $\mathrm{SH} 2$ domain, we demonstrated that this PLA-based methodology is a promising platform for the interrogation of other domain-based interactions. We showed that PTB and substrate-trapping PTP domains are capable of detecting EGFR phosphorylation. Although the $\mathrm{SH} 2$ domain is the most prevalent type of phosphotyrosine binding domain, integration of these other domains into the phosphorylation profiling is advantageous in that they allow for a larger coverage of tyrosine phosphorylation sites.

One obstacle to developing a customized SH2-PLA method for phosphorylated proteins will be preparation of a positive control. The original TaqMan Protein Assay is designed to quantify protein expression, making a purified protein target the most suitable control for determining assay performance. However, in the case of the SH2-PLA, a protein interaction assay assessing phosphorylation of a target protein, preparation of a suitable control is not a trivial task. For example, since SH2 domains may bind to a multiple tyrosine phosphorylation sites on the target protein, an appropriate positive control suitable for spike-in experiments should be phosphorylated on all $\mathrm{SH} 2$ binding sites and contain the antibody binding motif. We sidestepped this issue by establishing tyrosine phosphorylation standards and quantifying the absolute amount of tyrosine phosphorylation in the given sample, thereby estimating the assay detection limit. While this approach is applicable to any tyrosine phosphorylated protein target, similar approaches could also be tailored for other domains recognizing post-translational modification sites on cellular proteins
[55]. This feature as well as the universality of GSTtagging could allow SH2-PLA to serve as a prototype for the development of powerful, convenient modular domain based proteomic tools [45].

\section{Conclusions}

We have developed SH2-PLA, an alternative in-solution homogenous SH2 domain binding assay based on proximity ligation and real-time PCR. Using SH2-pEGFR interactions as the assay target, we showed that SH2-PLA has sufficient specificity, a very low limit of detection, a 1-2 order of magnitude linear range, and high reproducibility. In experiments with various EGF-stimulated cells, we confirmed good agreement between SH2-PLA and established far-Western assay results. Further, we found that SH2-PLA is sensitive enough to detect the relatively low level of pEGFR in lung cancer tissues without enrichment of pTyr-containing proteins. To our knowledge, this is the first report describing a microliter-scale assay for the detection of interaction between a recombinant $\mathrm{SH} 2$ domain probe and EGFR in cell lysate. This method provides significant improvement over traditional protein interaction assays requiring large sample input. With the low sample requirement and short assay runtime, SH2-PLA can provide a useful platform on which to develop high throughput modular domain binding assays applicable in both basic and translational cancer research.

\section{Methods}

\section{Cell culture and sample preparation}

Epidermoid carcinoma cell line A431 and monkey kidney fibroblast-like cell line Cos1 were maintained in DMEM supplemented with $10 \%$ fetal bovine serum and $0.1 \%$ penicillin/streptomycin (Mediatech). For EGF stimulation, overnight starved cells were stimulated with $50 \mathrm{ng} / \mathrm{ml}$ (0.37 nM) human recombinant Epidermal Growth Factor (EGF, Millipore Upstate) for $5 \mathrm{~min}$ and immediately lysed in Sample Lysis buffer (Applied Biosystems) with $1 \mathrm{mM}$ phenyl methyl sulfonyl fluoride (PMSF), $1 \mathrm{mM}$ sodium orthovanadate, and $5 \mu \mathrm{g} / \mathrm{ml}$ Aprotinin (Sigma A6279). For the cell titration experiment (Fig. 4a), two-fold serial dilutions ranging from 48 to $5 \times 10^{4} \mathrm{~A} 431$ cells were seeded in a 96-well plate. Cells were starved for $16 \mathrm{~h}$, stimulated with EGF, harvested, and lysed in $50 \mu \mathrm{l}$ of the Cell Lysis Reagent (Applied Biosystems) with $1 \mathrm{mM}$ PMSF, $1 \mathrm{mM}$ sodium orthovanadate, and $5 \mu \mathrm{g} / \mathrm{ml}$ Aprotinin. Cleared lysates were used in SH2-PLA assay with the Vav2 SH2 domain. For time course and dose response experiments (Fig. 4b), cells were stimulated at different times (0-300 s) and doses (0-200 ng/ml). Immediately after stimulation, culture media was poured off and the dishes were snap frozen in liquid nitrogen. Frozen dishes were incubated with $300 \mu \mathrm{l}$ Sample Lysis Buffer. Non small cell lung cancer tissues, originally banked at the Moffitt Cancer Center 
under its IRB protocol, were provided by Eric Haura (Moffitt Cancer Center) without clinical or biochemical information. The OCT-embedded frozen tissues were crushed, lysed in Sample Lysis Buffer, and solubilized using the Cryoprep and S2 homogenizer systems (Covaris). Cleared lysates were stored at $-80^{\circ} \mathrm{C}$.

\section{GST fusion constructs}

GST fusion proteins containing the Grb2 SH2 (amino acids 58-159), PLC 1 SH2-SH2 (542-759), Vav2 SH2 (665-774), and ShcA PTB (127-317) were prepared as previously described [23]. Briefly, bacterial culture was incubated with $0.1 \mathrm{mM}$ isopropyl $\beta$-D-1-thiogalactopyranoside (IPTG) and incubated at $16{ }^{\circ} \mathrm{C}$ for $24 \mathrm{~h}$. After harvesting bacteria, proteins were affinity-purified on glutathione-Sepharose beads. Protein concentration was determined by Bradford assay (Bio-Rad), purity of protein was confirmed by SDS-PAGE, concentration was adjusted to $0.1 \mu \mathrm{g} / \mu \mathrm{l}$ with $10 \%$ Glycerol-PBS, and stored at $-80{ }^{\circ} \mathrm{C}$. Similarly tyrosine phosphatase domain cDNA for human PTP1B (1-321, wild type and substrate trapping D181A mutant) and TC-PTP (1-354, wild type), both gifts from M.L. Tremblay, McGill University, were inserted into pGEX-6P1 (GE Healthcare), expressed in bacteria, purified, and stored at $-80{ }^{\circ} \mathrm{C}$.

\section{Western and far-Western blotting}

$25 \mu \mathrm{g}$ (A431 and Cos1) or $40 \mu \mathrm{g}$ (lung cancer tissues) of lysates were separated by SDS-PAGE and transferred to nitrocellulose membranes. Far-Western and Western blotting analyses were carried out as previously described $[6,7,23]$. Replica membranes were incubated with 200 nM GST fusion proteins in $5 \%$ fat-free milk dissolved in TBST $(150 \mathrm{mM} \mathrm{NaCl}, 10 \mathrm{mM}$ Tris- $\mathrm{HCl}$ [pH 8.0], and $0.05 \%$ Tween-20) for $2 \mathrm{~h}$, washed for $20 \mathrm{~min}$, and specific bands were visualized by chemiluminescence. Blots were stripped and reprobed with anti-EGFR (Santa Cruz Biotechnology), anti-phosphotyrosine (Cell Signaling), and anti-actin (Santa Cruz Biotechnology) antibodies. For quantitative far-Western analysis (Fig. 4b), band intensities were quantitated using ImageJ densitometry software (National Institutes of Health). For estimation of the absolute amount of tyrosine phosphorylation (Fig. 3 and Additional file 1: Figure S4), anti-phosphotyrosine Western blots were quantified using the LI-COR Odyssey IR detection system (LI-COR Biosciences).

\section{ICAM1 protein expression assay}

Under the test site agreement, the TaqMan Protein Expression Assay kit was supplied from Applied Biosystems, part of Life Technologies. The supplied items included ICAM1 PLA assay probes; Raji B-cell lymphoma control lysate; Lysate Dilution Buffer; Assay Probe Dilution Buffer; Ab/Prox-Oligo Dilution Buffer; Assay Probe Storage
Buffer; 5' Prox-Oligo; 3' Prox-Oligo; DNA ligase; Ligation Dilution Buffer; Ligation Reaction Buffer; protease; Universal PCR Assay; Fast Master Mix; Cell Lysis Reagent; Cell Resuspension Buffer; and an assay protocol. Additional reagents required for the assay were purchased from Applied Biosystems or other suppliers.

The Raji cell lysate ( 250 cell equivalent per $\mu \mathrm{l}$ ) was serially 2 -fold diluted in the Lysate Dilution Buffer in a 96-well plate on ice. $2 \mu \mathrm{l}$ of $0.5 \mathrm{nM} \mathrm{3'}$ and 5' ICAM1 assay probe mixture was added to $2 \mu \mathrm{l}$ lysate in quadruplicate, sealed with MicroAmpTM Clear Adhesive Film, and incubated for $60 \mathrm{~min}$ at $37^{\circ} \mathrm{C}$. Subsequently $96 \mu \mathrm{l}$ of DNA ligase in Ligation Dilution Buffer was added to the sample wells, resealed and incubated at $37^{\circ} \mathrm{C}$ for $10 \mathrm{~min}$ to allow for the ligation reaction. The reaction was stopped by adding $2 \mu \mathrm{l}$ of diluted protease solution to each well and the sealed plate was incubated at $37^{\circ} \mathrm{C}$ for $10 \mathrm{~min}$ followed by heat inactivation at $95^{\circ} \mathrm{C}$ for $5 \mathrm{~min}$.

For real-time PCR reactions, $9 \mu \mathrm{l}$ of the ligation product was mixed with $1 \mu$ l Universal PCR Assay solution and $10 \mu \mathrm{l}$ of TaqMan Protein Expression Fast Master Mix in a real time PCR reaction plate. The ligation plate was sealed with MicroAmp Optical Adhesive Film, centrifuged at $1000 \mathrm{rpm}$ for $10 \mathrm{~s}$, and real-time PCR was performed using the StepOnePlus System with fast cycling condition (Applied Biosystems). The real-time PCR data including $\mathrm{Ct}$ values at threshold 0.2 with automatic baseline setting were exported from StepOne software and plotted by $\mathrm{Ct}$ values (cycle) and lysate input (cell equivalent per $\mu \mathrm{l}$ ). Intra-assay variation was assessed using \% CV of quadruplicates and inter-assay by Pearson correlation using Prism 6 software (GraphPad). For linearity assessment, $\mathrm{Ct}$ values were fitted by log-linear regression and R-squared values were calculated.

\section{Anti-GST and anti-EGFR probe development}

Conjugation of biotinylated antibodies and oligonucleotide tags (5' and 3' Prox-Oligos) was carried out following the TaqMan Protein Expression Assay Probe Development Protocol (Applied Biosciences). To generate the anti-EGFR 3' (or 5') SH2-PLA probe, biotinylated anti-human EGFR antibody BAF231 (R\&D Systems) was incubated with 3' (or 5') Prox-Oligo at $200 \mathrm{nM}$ in Ab/Prox-Oligo Dilution Buffer at room temperature for $1 \mathrm{~h}$ with gentle rocking. The resulting $3^{\prime}$ anti-EGFR probe was diluted to $10 \mathrm{nM}$ with Assay Probe Storage buffer and stored at $-20{ }^{\circ} \mathrm{C}$. The anti-GST $5^{\prime}$ (or 3') SH2-PLA probe was prepared in the same manner using a biotinylated anti-GST antibody A00202 (Genscript) and 5' (or 3') Prox-Oligo.

To test the activity of the anti-GST $5^{\prime}$ and $3^{\prime} \mathrm{SH} 2-$ PLA probes, GST protein, purified and stored in $-80{ }^{\circ} \mathrm{C}$ at $0.1 \mu \mathrm{g} / \mu \mathrm{l}$ in $10 \%$ glycerol-PBS, was adjusted to $0.1 \mathrm{ng} / \mu \mathrm{l}$ with Cell Resuspension Buffer and 2-fold serially diluted in a 96-well plate on ice. The anti-GST 5' and 3' SH2- 
PLA probes were diluted in Assay Probe Dilution Buffer. The same volume of anti-GST 5' and 3' SH2-PLA probes were gently mixed, and $2 \mu \mathrm{l}$ of mixed assay probes were added to $2 \mu$ of serially diluted GST protein in duplicate (GST concentration: $0.13 \mathrm{nM}-4.17 \mathrm{nM}$ ). To test the activity of anti-EGFR SH2-PLA probes, protein lysates of $50 \mathrm{ng} / \mathrm{ml}$ EGF-stimulated and control A431 cells were adjusted to $0.03 \mu \mathrm{g} / \mu \mathrm{l}$ with Cell Resuspension Buffer and then 2-fold serially diluted in a 96-well plate on ice. 5' and 3' anti-EGFR Prox-Oligo probes were diluted in Assay Probe Dilution Buffer. The equal volumes of the 5' and 3' probes were gently mixed, and $2 \mu \mathrm{l}$ of the mixture was added to $2 \mu \mathrm{l}$ of serially diluted lysate in duplicate (final concentration of $0.93-30 \mu \mathrm{g} / \mathrm{ml}$ ). Subsequent ligation reaction, protease treatment and real-time PCR were performed as described for the "ICAM1 protein expression assay." In these experiments, the Ct value for unstimulated A431 lysate in a combination with anti-GST 5' and antiEGFR 3' probes was used as a negative control (NC). The pY1068 blocker peptide for the Grb2 binding site on EGFR was purchased from Cell Signaling.

\section{SH2-PLA assay}

Method 1: Lysate dilutions in Cell Resuspension Buffer were incubated with anti-EGFR 3' PLA Prox-Oligo probe (final concentration $0.5 \mathrm{nM}$ ) for $1.5 \mathrm{~h}$ at $4{ }^{\circ} \mathrm{C}$ [Solution 1]. GST-SH2 protein was incubated with anti-GST 5' ProxOligo probe (final concentration $0.1 \mu \mathrm{g} / \mathrm{ml}$ and $0.5 \mathrm{nM}$, respectively) for $1.5 \mathrm{~h}$ at $4{ }^{\circ} \mathrm{C}$ [Solution 2]. Then $2 \mu \mathrm{l}$ of the Solution 1 and Solution 2 were incubated at $4{ }^{\circ} \mathrm{C}$ for $1.5 \mathrm{~h}$ in the thermal cycler to induce a quaternary complex of [anti-EGFR 3'Prox-Oligo probe:phosphorylated EGFR:GST-SH2 protein:anti-GST 5' Prox-Oligo probe] (Fig. 1b). Subsequent ligation reaction, protease treatment and real-time PCR were performed as described for the "ICAM1 protein expression assay."

Method 2: GST-SH2 or GST control proteins were diluted to $0.1 \mu \mathrm{g} / \mathrm{ml}$ in Cell Resuspension Buffer and incubated with the same volume of EGF-stimulated or unstimulated cell lysate for $1.5 \mathrm{~h}$ at $4{ }^{\circ} \mathrm{C}$ (for SH2-EGFR binding). Then $2 \mu \mathrm{l}$ of the $\mathrm{SH} 2$ bound lysates were incubated with $2 \mu \mathrm{l}$ of $0.5 \mathrm{nM}$ Prox-Oligo probe mixture (anti-GST $5^{\prime}+$ anti-EGFR $3^{\prime}$ ) in a thermal cycler at $4{ }^{\circ} \mathrm{C}$ for $1.5 \mathrm{~h}$ to form a quaternary complex of [anti-EGFR 3' Prox-Oligo probe:phosphorylated EGFR:GST-SH2 protein:anti-GST 5' Prox-Oligo probe] (Additional file 1: Figure S2). Subsequent ligation reaction, protease treatment and real-time PCR were performed as described in "ICAM1 protein expression assay."

\section{Quantification of EGFR phosphotyrosines}

A GST fusion of wild-type murine type IV c-Abl was produced from baculovirus-infected Sf9 insect cells as described previously [24]. GST-Abl was purified by incubating lysates with glutathione-agarose beads (GE) at $4{ }^{\circ} \mathrm{C}$ for $1.5 \mathrm{~h}$, washing extensively in Buffer E (50 mM Tris $\mathrm{pH} 8.0,150 \mathrm{mM} \mathrm{NaCl}, 5 \%$ glycerol, $2 \mathrm{mM}$ dithiothreitol) and eluting with Buffer E plus $20 \mathrm{mM}$ reduced glutathione. Prior to the malachite green free phosphate assay, the GST-Abl solution was concentrated to about $0.5 \mu \mathrm{g} / \mu \mathrm{l}$ with an Amicon Ultra-4 Centrifugal Filter $(10 \mathrm{~K}$, Millipore).

Malachite green phosphate assays were performed according to the manufacturer's instructions (Abnova). Briefly, purified GST-Abl and PTP cocktail (GST-PTP1B and GST-TcPTP) proteins are incubated at a 5:1 molar ratio at $37{ }^{\circ} \mathrm{C}$ for $2 \mathrm{~h}$, then mixed with acidic solution for quenching. Serially diluted reactions were visualized with $1 \mathrm{mM}$ malachite green and quantified by absorbance at $620 \mathrm{nM}$ using the M1000 Pro plate reader (Tecan). A standard curve for the absorbance and phosphate input $\left(\mathrm{PO}_{4}^{3-}\right)$ was obtained by adding a serially diluted free phosphate standard into the untreated c-Abl solution. The change in phosphotyrosine (as assessed by $\mathrm{PO}_{4}^{3-}$ release) in the $\mathrm{c}$-Abl solution during the PTP treatment $(\triangle \mathrm{Abl}$ $\mathrm{PO}_{4}^{3-}$ ) was estimated with the free phosphate standard curve (Fig. 3a).

For comparative dot blotting, Abl proteins and Cos1 lysates were diluted in SDS sample buffer, boiled, and manually spotted in triplicates on a nitrocellulose membrane $(0.003$ to $100 \mathrm{ng}$ in $0.5 \mu \mathrm{l}$ per spot). The dried membrane was incubated in Buffer $\mathrm{T}$ (10 mM CAPS $\mathrm{pH}$ 11.0, $20 \%$ methanol) for $30 \mathrm{~min}$, blocked in $5 \%$ nonfat milk-TBST for $1 \mathrm{~h}$, and incubated with antiphosphotyrosine antibody (PY100, Cell Signaling) overnight at $4{ }^{\circ} \mathrm{C}$. After washing with TBST (10 mM Tris pH8.0, $150 \mathrm{mM} \mathrm{NaCl}, 0.05 \%$ Tween 20), membranes were incubated with IRdye conjugated goat anti-mouse antibody, washed, and bound antibody was detected using an infrared imaging system (Odyssey, LI-COR Bioscience). Raw signal of individual dots was quantified using Odyssey 3.03 and ImageStudio software (LI-COR Biosciences) and plotted against protein quantity (Fig. 3b).

The absolute amount of phosphotyrosine in the Cos1 sample, was estimated by the linear standard curve generated by serially diluting the Abl standard (Fig. 3b). Of note, although a trace amount of tyrosine phosphorylation is detectable in PTP-treated Abl, at low concentrations (3.1-0.02 ng per spot) the untreated Abl spots had a linear signal profile and were unaffected by the trace PTP-treated Abl signal. Thus the pTyr amount of the target sample can be interpolated using the linear $\mathrm{Abl}$ calibration curve (Fig. 3b). For EGFR band quantification, $10 \mu \mathrm{g}$ of A431 and Cos1 cell samples were separated on SDS-PAGE, transferred to nitrocellulose in Buffer T, and immunoblotted with anti-phosphotyrosine antibody as described above. For EGFR band analysis, the mean values of whole lanes of EGF-stimulated samples were compared 
to EGFR size bands in Cos1 cells, which were then used to approximate the amount of phosphotyrosine on EGFR in A431 cells (Additional file 1: Figure S4).

\section{Data analysis and statistical tests}

To evaluate assay performance, the $\mathrm{Ct}$ values were plotted against the lysate concentration $(\mu \mathrm{g} / \mathrm{ml})$ or cell number (cell per $\mu \mathrm{l}$ ) and compared with those of unstimulated control samples. The linear signal range was estimated using Microsoft Excel 2011 (Microsoft), Prism 6.0 (GraphPad), and ProteinAssist (Applied Biosystems) as appropriate. Outliers were excluded by the ROUT method in Prism 6.0 with $\mathrm{Q}=1.0 \%$ [25]. The intra-assay variation was determined by \%CV of $\mathrm{Ct}$ values from three technical replicates. Assay to assay (inter-assay) variability was assessed with normalized $\mathrm{Ct}$ values from three independent experiments, in which antibody binding, $\mathrm{SH} 2$ binding, ligation, protease treatment, and real-time PCR reactions were independently performed while using the same batch of cell lysate samples.

For fold change estimation, ProteinAssist v1.1 (Applied Biosystems), a software tool customized for TaqMan Protein Assays based on the $\Delta \mathrm{Ct}$ squared method, was used [12]. Relative quantification was performed using serial dilution data for EGF-stimulated and control samples (Fig. 2 and Additional file 1: Figure S3). Raw Ct values were directly imported into ProteinAssist which generated the $\Delta \mathrm{Ct}$-by-input quantity plots. The quantification threshold, outlier detection, and linear range detection were set to default values and the automatically assigned linear range was manually corrected. The $\log _{2}$ fold change with $95 \%$ confidential intervals between the stimulated and unstimulated samples for Grb2 $\mathrm{SH} 2$ binding was estimated by comparing each $\mathrm{X}$-intercept (at quantification threshold set at 2.0) of the linear regions of the $\Delta \mathrm{Ct}$ plots for the stimulated and unstimulated samples.

For clinical samples, the statistical significance of sample $\mathrm{Ct}$ value differences were assessed using an ordinary one-way ANOVA test with Dunnett's multiple comparisons test using Prism 6.0.

\section{Additional file}

Additional file 1: Figure S1. Performance of homogeneous in-solution PLA. Figure S2. Experimental workflow for SH2-PLA Method 2. Figure S3. Fold change calculation. Figure S4. SH2-PLA limit of detection estimation.

\section{Abbreviations}

SH2: Src homology 2; PLA: Proximity ligation assay; EGFR: Epidermal growth factor receptor; pEGFR: Tyrosine phosphorylated EGFR; GST: Glutathione S-transferase; pTyr: Phosphotyrosine; PTB: Phosphotyrosine binding; PTP: Protein tyrosine phosphatase; PCR: Polymerase chain reaction; MS: Mass spectrometry.

\section{Competing interests}

Reagents for TaqMan Protein Assays were partially supplied by Applied Biosystems, part of Life Technologies Corporation (LTC) under the TaqMan Protein Expression Assays Test Site Agreement between LTC and the University of Connecticut Health Center. The authors have no financial or other interest in objects or entities mentioned in this paper.

\section{Authors' contributions}

KM designed research; CMT, LRB, MO-I, and KM performed research; CMT, MO-I, and KM analyzed data; CMT and KM wrote the paper. All authors read and approved the final manuscript.

\section{Acknowledgements}

We thank Elana Swartzman, Mark Shannon, and Tina Settineri for helpful discussions concerning assay development; Gregory Gallo for helping set up the test site agreement; Eric Haura for providing lung cancer samples; Michel Tremblay for providing the PTP1B and TC-PTP CDNAs; Ahmed Elmokadem for helping with preliminary PTP experiments; Joshua Jadwin for editing this manuscript, and Bruce Mayer for his continuous encouragement and support. This study was partly supported by grant CA1154966 from the National Institutes of Health and Quest for CURES (QFC) grant from the Leukemia and Lymphoma Society (to K.M.).

Received: 7 March 2015 Accepted: 17 May 2015

Published online: 26 June 2015

\section{References}

1. Yaffe MB. Phosphotyrosine-binding domains in signal transduction. Nat Rev Mol Cell Biol. 2002;3(3):177-86.

2. Kaneko T, Joshi R, Feller SM, Li SS. Phosphotyrosine recognition domains: the typical, the atypical and the versatile. Cell Commun Signal. 2012;10(1):32.

3. Liu BA, Jablonowski K, Raina M, Arce M, Pawson T, Nash PD. The human and mouse complement of $\mathrm{SH} 2$ domain proteins-establishing the boundaries of phosphotyrosine signaling. Mol Cell. 2006;22(6):851-68.

4. Machida K, Mayer BJ. The SH2 domain: versatile signaling module and pharmaceutical target. Biochim Biophys Acta. 2005;1747(1):1-25.

5. Schweigel H, Geiger J, Beck F, Buhs S, Gerull H, Walter U, et al. Deciphering of ADP-induced, phosphotyrosine-dependent signaling networks in human platelets by Src-homology 2 region (SH2)-profiling. Proteomics. 2013;13(6):1016-27.

6. Machida K, Eschrich S, Li J, Bai Y, Koomen J, Mayer BJ, et al. Characterizing tyrosine phosphorylation signaling in lung cancer using $\mathrm{SH} 2$ profiling. PLoS One. 2010;5(10):e13470.

7. Machida K, Thompson CM, Dierck K, Jablonowski K, Karkkainen S, Liu B, et al. High-throughput phosphotyrosine profiling using SH2 domains. Mol Cell. 2007;26(6):899-915.

8. Dierck K, Machida K, Voigt A, Thimm J, Horstmann M, Fiedler W, et al. Quantitative multiplexed profiling of cellular signaling networks using phosphotyrosine-specific DNA-tagged SH2 domains. Nat Methods. 2006;3(9):737-44.

9. Nollau P, Mayer BJ. Profiling the global tyrosine phosphorylation state by Src homology 2 domain binding. Proc Natl Acad Sci U S A. 2001;98(24):13531-6.

10. Machida K, Khenkhar M, Nollau P. Deciphering phosphotyrosine-dependent signaling networks in cancer by SH2 profiling. Genes Cancer. 2012;3(5-6):353-61.

11. Solier $\mathrm{C}$, Langen $\mathrm{H}$. Antibody-based proteomics and biomarker research - current status and limitations. Proteomics. 2014;14(6):774-83.

12. Ruff DW, Shannon ME, Chen S-M, Fredriksson S, Landegren U. Proximity ligation assay for protein quantification. PCR Technol Current Innovations. 2013;393-407.

13. Blokzijl A, Nong R, Darmanis S, Hertz E, Landegren U, Kamali-Moghaddam M. Protein biomarker validation via proximity ligation assays. Biochim Biophys Acta. 2014;1844(5):933-9.

14. Fredriksson S, Gullberg M, Jarvius J, Olsson C, Pietras K, Gustafsdottir SM, et al. Protein detection using proximity-dependent DNA ligation assays. Nat Biotechnol. 2002;20(5):473-7.

15. Stahlberg A, Thomsen C, Ruff D, Aman P. Quantitative PCR analysis of DNA, RNAs, and proteins in the same single cell. Clin Chem. 2012;58(12):1682-91. 
16. Gustafsdottir SM, Wennstrom S, Fredriksson S, Schallmeiner E, Hamilton AD, Sebti SM, et al. Use of proximity ligation to screen for inhibitors of interactions between vascular endothelial growth factor $A$ and its receptors. Clin Chem. 2008;54(7):1218-25.

17. Rhett JM, Ongstad EL, Jourdan J, Gourdie RG. Cx43 associates with Na(v)1.5 in the cardiomyocyte perinexus. J Membr Biol. 2012;245(7):411-22.

18. Naegle KM, White FM, Lauffenburger DA, Yaffe MB. Robust co-regulation of tyrosine phosphorylation sites on proteins reveals novel protein interactions. Mol Biosyst. 2012;8(10):2771-82.

19. Swartzman E, Shannon M, Lieu P, Chen SM, Mooney C, Wei E, et al. Expanding applications of protein analysis using proximity ligation and qPCR. Methods. 2010;50(4):S23-6.

20. Ruff D, MacArthur C, Tran H, Bergseid J, Tian J, Shannon M, et al. Applications of quantitative polymerase chain reaction protein assays during reprogramming. Stem Cells Dev. 2012;21(4):530-8.

21. Pfister C, Pfrommer H, Tatagiba MS, Roser F. Detection and quantification of farnesol-induced apoptosis in difficult primary cell cultures by TaqMan protein assay. Apoptosis. 2013;18(4):452-66.

22. Lundberg M, Thorsen SB, Assarsson E, Villablanca A, Tran B, Gee N, et al. Multiplexed homogeneous proximity ligation assays for high-throughput protein biomarker research in serological material. Mol Cell Proteomics. 2011;10(4):M110 004978.

23. Machida K, Mayer BJ. Detection of protein-protein interactions by far-Western blotting. Methods Mol Biol. 2009;536:313-29.

24. Mayer BJ, Baltimore D. Mutagenic analysis of the roles of $\mathrm{SH}_{2}$ and $\mathrm{SH} 3$ domains in regulation of the Abl tyrosine kinase. Mol Cell Biol. 1994;14(5):2883-94.

25. Motulsky HJ, Brown RE. Detecting outliers when fitting data with nonlinear regression - a new method based on robust nonlinear regression and the false discovery rate. BMC Bioinformatics. 2006;7:123.

26. Okutani T, Okabayashi Y, Kido Y, Sugimoto Y, Sakaguchi K, Matuoka K, et al. Grb2/Ash binds directly to tyrosines 1068 and 1086 and indirectly to tyrosine 1148 of activated human epidermal growth factor receptors in intact cells. J Biol Chem. 1994;269(49):31310-4.

27. Bedrin MS, Abolafia CM, Thompson JF. Cytoskeletal association of epidermal growth factor receptor and associated signaling proteins is regulated by cell density in IEC-6 intestinal cells. J Cell Physiol. 1997;172(1):126-36.

28. Moores SL, Selfors LM, Fredericks J, Breit T, Fujikawa K, Alt FW, et al. Vav family proteins couple to diverse cell surface receptors. Mol Cell Biol. 2000;20(17):6364-73.

29. Hause Jr RJ, Leung KK, Barkinge JL, Ciaccio MF, Chuu CP, Jones RB. Comprehensive binary interaction mapping of $\mathrm{SH} 2$ domains via fluorescence polarization reveals novel functional diversification of ErbB receptors. PLoS One. 2012;7(9):e44471

30. Liu BA, Jablonowski K, Shah EE, Engelmann BW, Jones RB, Nash PD. SH2 domains recognize contextual peptide sequence information to determine selectivity. Mol Cell Proteomics. 2010;9(11):2391-404.

31. Huang H, Li L, Wu C, Schibli D, Colwill K, Ma S, et al. Defining the specificity space of the human SRC homology 2 domain. Mol Cell Proteomics. 2008;7(4):768-84.

32. Jones RB, Gordus A, Krall JA, MacBeath G. A quantitative protein interaction network for the ErbB receptors using protein microarrays. Nature. 2006:439(7073):168-74

33. Gehring A, He X, Fratamico P, Lee J, Bagi L, Brewster J, et al. A high-throughput, precipitating colorimetric sandwich ELISA microarray for shiga toxins. Toxins (Basel). 2014;6(6):1855-72.

34. Fernando SA, Wilson GS. Multiple epitope interactions in the two-step sandwich immunoassay. J Immunol Methods. 1992;151(1-2):67-86.

35. Wolf BA, Garrett NC, Nahm MH. The "hook effect": high concentrations of prostate-specific antigen giving artifactually low values on one-step immunoassay. N Engl J Med. 1989;320(26):1755-6.

36. Julien SG, Dube N, Hardy S, Tremblay ML. Inside the human cancer tyrosine phosphatome. Nat Rev Cancer. 2011;11(1):35-49.

37. Wagner MJ, Stacey MM, Liu BA, Pawson T. Molecular mechanisms of SH2- and PTB-domain-containing proteins in receptor tyrosine kinase signaling. Cold Spring Harb Perspect Biol. 2013;5(12):a008987.

38. Kawamoto T, Takahashi K, Nishi M, Kimura T, Matsumura T, Taniguchi S. Quantitative assay of epidermal growth factor receptor in human squamous cell carcinomas of the oral region by an avidin-biotin method. Jpn J Cancer Res. 1991;82(4):403-10.
39. Kawamoto T, Sato JD, Le A, Polikoff J, Sato GH, Mendelsohn J. Growth stimulation of A431 cells by epidermal growth factor: identification of high-affinity receptors for epidermal growth factor by an anti-receptor monoclonal antibody. Proc Natl Acad Sci U S A. 1983;80(5):1337-41.

40. Csordas G, Santra M, Reed CC, Eichstetter I, McQuillan DJ, Gross D, et al. Sustained down-regulation of the epidermal growth factor receptor by decorin. A mechanism for controlling tumor growth in vivo. J Biol Chem. 2000;275(42):32879-87.

41. Finka A, Goloubinoff P. Proteomic data from human cell cultures refine mechanisms of chaperone-mediated protein homeostasis. Cell Stress Chaperones. 2013;18(5):591-605.

42. Hornbeck PV, Kornhauser JM, Tkachev S, Zhang B, Skrzypek E, Murray B, et al. PhosphoSitePlus: a comprehensive resource for investigating the structure and function of experimentally determined post-translational modifications in man and mouse. Nucleic Acids Res. 2012;40(Database issue):D261-70.

43. Rikova K, Guo A, Zeng Q, Possemato A, Yu J, Haack H, et al. Global survey of phosphotyrosine signaling identifies oncogenic kinases in lung cancer. Cell. 2007;131(6):1190-203.

44. Liotta LA, Espina V, Mehta Al, Calvert V, Rosenblatt K, Geho D, et al. Protein microarrays: meeting analytical challenges for clinical applications. Cancer Cell. 2003;3(4):317-25.

45. Jadwin JA, Ogiue-Ikeda M, Machida K. The application of modular protein domains in proteomics. FEBS Lett. 2012;586(17):2586-96.

46. Liu BA, Engelmann BW, Jablonowski K, Higginbotham K, Stergachis AB, Nash PD. SRC homology 2 domain binding sites in insulin, IGF-1 and FGF receptor mediated signaling networks reveal an extensive potential interactome. Cell Commun Signal. 2012;10(1):27.

47. Liu BA, Engelmann BW, Nash PD. High-throughput analysis of peptide-binding modules. Proteomics. 2012;12(10):1527-46.

48. Oh D, Ogiue-lkeda M, Jadwin JA, Machida K, Mayer BJ, Yu J. Fast rebinding increases dwell time of Src homology $2(\mathrm{SH} 2)$-containing proteins near the plasma membrane. Proc Natl Acad Sci U S A. 2012;109(35):14024-9.

49. Mayer BJ. Perspective: dynamics of receptor tyrosine kinase signaling complexes. FEBS Lett. 2012;586(17):2575-9.

50. Morimatsu M, Takagi H, Ota KG, Iwamoto R, Yanagida T, Sako Y. Multiple-state reactions between the epidermal growth factor receptor and Grb2 as observed by using single-molecule analysis. Proc Natl Acad Sci U S A. 2007;104(46):18013-8.

51. Thorsen SB, Christensen SL, Wurtz SO, Lundberg M, Nielsen BS, Vinther L, et al. Plasma levels of the MMP-9:TIMP-1 complex as prognostic biomarker in breast cancer: a retrospective study. BMC Cancer. 2013;13:598.

52. Gustafsdottir SM, Nordengrahn A, Fredriksson S, Wallgren P, Rivera E, Schallmeiner $\mathrm{E}$, et al. Detection of individual microbial pathogens by proximity ligation. Clin Chem. 2006;52(6):1152-60.

53. Darmanis S, Nong RY, Hammond M, Gu J, Alderborn A, Vanelid J, et al. Sensitive plasma protein analysis by microparticle-based proximity ligation assays. Mol Cell Proteomics. 2010;9(2):327-35.

54. Tavoosidana G, Ronquist G, Darmanis S, Yan J, Carlsson L, Wu D, et al. Multiple recognition assay reveals prostasomes as promising plasma biomarkers for prostate cancer. Proc Natl Acad Sci U S A. 2011;108(21):8809-14.

55. Reinhardt HC, Yaffe MB. Phospho-Ser/Thr-binding domains: navigating the cell cycle and DNA damage response. Nat Rev Mol Cell Biol. 2013;14(9):563-80.

\section{Submit your next manuscript to BioMed Central and take full advantage of:}

- Convenient online submission

- Thorough peer review

- No space constraints or color figure charges

- Immediate publication on acceptance

- Inclusion in PubMed, CAS, Scopus and Google Scholar

- Research which is freely available for redistribution

Submit your manuscript at www.biomedcentral.com/submit

C Biomed Central 